\title{
Thermal degradation and fire behaviour of thermal insulation materials based on food crop by-products
}

\author{
M. Palumbo ${ }^{\mathrm{a}}$, J. Formosa ${ }^{\mathrm{a}, \mathrm{b}}$ and A.M. Lacasta ${ }^{\mathrm{a} *}$ \\ ${ }^{a}$ Escola Politècnica Superior de l'Edificació de Barcelona, Universitat Politècnica de Catalunya, \\ Barcelona, Spain. \\ ${ }^{b}$ Departament de Ciència dels Materials i Enginyeria Metal·lúrgica, Universitat de Barcelona, \\ Spain \\ *Corresponding author: UPC-EPSEB, Av Dr. Marañon 44-50 08028 Barcelona \\ Tel: +34/934016816 Fax: +34/934017700 \\ E-mail: ana.maria.lacasta@upc.edu
}

Keywords: crop by-products; natural thermal insulations; fire behaviour; flammability; pyrolysis combustion flow calorimetry

\begin{abstract}
Natural thermal insulation materials developed from renewable crop by-products and natural binders are analysed in terms of their thermal degradation and fire behaviour. A pyrolysis combustion flow calorimetre (PCFC) is used to characterise some kinds of crop by-products, including rice husk, corn pith and barley straw. This technique is complemented with a TG analysis. Six thermal insulation materials, formulated with such crop by-products and two kind of natural binders, corn starch and sodium alginate, are developed and analysed. PCFC results show an improvement when sodium alginate is incorporated, especially in the corn pith composite. Fire reaction tests are also performed that yield results which are in qualitative agreement with the small-scale tests.
\end{abstract}




\section{Introduction}

The building sector is moving towards new approaches to energy efficient design, which includes not only the decrease of the thermal transmittance of the building envelope but also the improvement and use of natural and locally available building materials. The use of industrial crops and food crop by-products as raw materials for composites to be used in building applications is an interesting alternative to conventional products [1-4]. Although much of the research has been focused on the reinforcement in composites and the development of high and medium density boards, there is an increasing interest in their use in natural thermal insulations [5]. Together with the good hygrothermic properties of these natural materials, their availability from renewable resources is considered as one of their main advantages compared with other petroleum-derived insulations. In addition, the use of food crop by-products has a positive environmental impact because implies the revaluation of existing natural resources. All of these beneficial aspects encourage its use in building insulation, but it is necessary to analyse their potential response under real situations, in particular their behaviour in case of fire, before establish the feasibility of their use. The fire reaction of the vegetal compounds and the developed composites is a crucial aspect that should be well-known and improved. Several authors have analysed the thermal degradation and flammability of different natural fibres and composites that include such fibres [6]. Alvarez et al. [7] performed a thermal analysis of cellulose derivatives/starch blends with different sisal short fibre content, and found that the addition of the sisal fibres produced no significant effect on the thermal degradation of the composite materials in comparison with the matrix alone. Yao et al. [8] investigated the thermal decomposition processes of 10 types of natural fibres commonly used in the polymer composite industry. These fibres included wood, bamboo, agricultural residue, and bast fibres. Dorez et al. [9] considered cellulose, hemp, flax, sugar cane and bamboo as natural fibres, and polybutylene succinate (PBS) as a polymer matrix. The treatments of fibres prior to their use in composites have also been analysed in terms of possible changes in their thermal degradation properties. For example, Rana et al. [10] used a simple solvent and catalyst acetylation method on jute 
fibres and obtained that the thermal stability of acetylated jute was higher than the untreated jute. The addition of flame retardants in lignocellulosic materials has also been widely studied $[9,11,12]$. These kinds of retardants include phosphorus-based ones like di-ammonium phosphate (DAP) and sulfamic acid salts such as ammonium sulphamate [11].

The strategy commonly used to analyse thermal degradation and fire behaviour combines smallscale thermal analysis such as Thermogramivetric Analysis (TGA) and/or Differential Scanning Calorimetry (DSC) with fire reaction tests such as cone calorimetre and Limiting Oxygen Index (LOI). However, the use of a microcalorimetre known as Pyrolysis Combustion Flow Calorimetre (PCFC) is becoming also usual $[13,14]$. Microscale combustion calorimetry combines thermal analysis and oxygen consumption calorimetry thus enabling the determination of Heat Release Capacity (HR) and Heat Release Rate (HRR) of small samples. Data from the PCFC have been shown to correlate well with other established fire tests $[15,16]$ and it has been approved as an ASTM International Standard for plastics and other solid materials [17].

In this study, three different crop by-products have been used for the development of six natural thermal insulations, using corn starch and sodium alginate as binders. Both the composites and the raw materials are analysed in terms of their thermal stability and fire behaviour.

\section{Experimental}

\subsection{Materials and formulations}

Three types of crop by-products were analysed: rice husk, corn pith and barley straw. Table 1 summarises their chemical composition according to the values reported in the literature. 
Table 1. Main chemical composition of vegetable materials

\begin{tabular}{lcccccc}
\hline Crop type & Cellulose (\%) & Hemicellulose $(\%)$ & Lignin $(\%)$ & Silica $(\%)$ & Ash (\%) & Ref. \\
\hline Rice husk & 24.3 & 24.3 & 14.3 & $9-14 *$ & 15.3 & {$[18,19]$} \\
Corn cob & $43.2-50.5$ & 31.0 & $14.6-15.0$ & & 2.2 & {$[20,21]$} \\
Barley straw & $31.0-45.0$ & $24.0-29.0$ & $14.0-15.0$ & 3.6 & $3-7$ & {$[19,20]$} \\
\hline
\end{tabular}

*Data for rice straw

Natural thermal insulations were formulated with the above vegetal materials. Two polysaccharides, supplied by Cargill S.A, were used as binders: corn starch and sodium alginate.

The formulations, presented in Table 2, were optimised in a previous work [22] in order to obtain suitable composites, which appearance is shown in Fig.1. Table 2 also shows the corresponding bulk densities. Since the thermal conductivity values are similar in all cases, the thickness required to achieve a given thermal resistance is the same in all cases. Therefore, insulations made with corn pith, which has the lowest density, will have the lowest mass per surface unit.

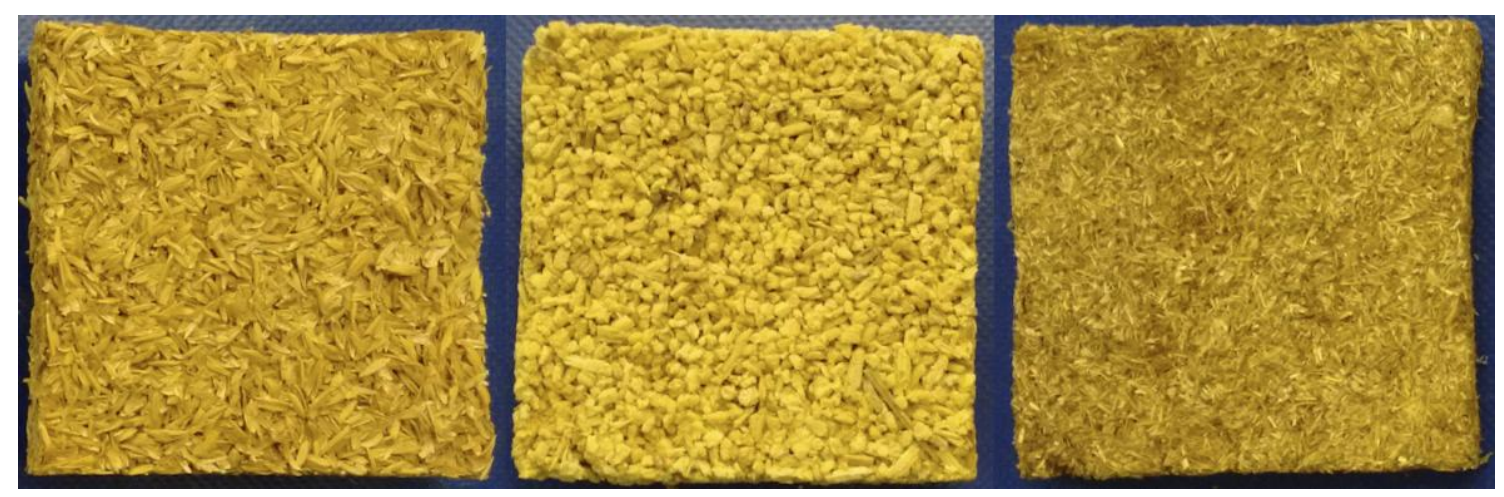

Figure 1. Thermal insulations formulated according to Table 2, from left to right rice husk, corn pith and barley straw based boards. 
Table 2. Formulations of natural thermal insulations and their corresponding densities.

\begin{tabular}{lccc}
\hline Thermal insulation & Vegetal fibre (\%) & Binder $(\%)$ & Density $\left(\mathrm{kg} / \mathrm{m}^{3}\right)$ \\
\hline Rice husk + starch & 71.4 & 28.6 & 223 \\
Corn pith + starch & 90.9 & 9.1 & 89 \\
Barley straw + starch & 83.3 & 16.7 & 141 \\
Rice husk + alginate & 89.3 & 10.7 & 189 \\
Corn pith + alginate & 97.1 & 2.9 & 58 \\
Barley straw + alginate & 94.3 & 5.7 & 98 \\
\hline
\end{tabular}

\subsection{Pyrolysis Combustion Flow Calorimetre}

Small-scale flammability tests were carried out on a Fire Testing Technology Pyrolysis Combustion Flow Calorimetre (PCFC). The heating rate at the pyrolyser was set to $60^{\circ} \mathrm{C} / \mathrm{min}$ up to a maximum temperature of $750^{\circ} \mathrm{C}$. Products from the anaerobic thermal degradation completed in a nitrogen atmosphere were mixed with a $20 \mathrm{~cm}^{3} / \mathrm{min}$ stream of oxygen prior to entering the combustion furnace at $900^{\circ} \mathrm{C}$.

\subsection{Thermogravimetric Analysis}

Thermogravimetric analysis (TGA) was performed in an inert atmosphere using a TA Instruments SDT Q600. Measurements were taken out under a nitrogen atmosphere with a heating rate of $10^{\circ} \mathrm{C} / \mathrm{min}$ from $30^{\circ} \mathrm{C}$ to $600^{\circ} \mathrm{C}$. For each experiment a mass of $5 \mathrm{mg} \pm 0.5 \mathrm{mg}$ was used and the flow rate of gas was $50 \mathrm{ml} / \mathrm{min}$.

\subsection{Ignition time and extinguishability}

A radiator device described in the Spanish Standard UNE 23.725-90 was employed to measure the ignition time and the degree of extinguishability of combustion. Samples of surface $70 x 70$ $\mathrm{mm}^{2}$ and variable thickness were placed on a metallic grid $3 \mathrm{~cm}$ below a heat source of $500 \mathrm{~W}$, which was removed and replaced after each ignition and extinction, respectively. The most 
important parameters determined were the number of ignitions and the average value of combustion extent during the 5 minutes of assay.

\subsection{Limiting Oxygen Index (LOI)}

The Limiting Oxygen Index was determined using the device described in UNE-EN ISO 45892. Samples of $70 \times 2 \times 0.5 \mathrm{~mm}$ were placed vertically in a test chimney. A gas mixture of nitrogen and oxygen was then blown through the chimney and the sample was ignited. This procedure was repeated a minimum of six times for each composite, the oxygen concentration of the gas mixture being changed every time in order to determine the concentration at which the sample burned.

\section{Results and discussion}

\subsection{PCFC analysis of crop products and binders}

Small samples of $10 \mathrm{mg}( \pm 0.5 \mathrm{mg})$ in mass were tested in the Pyrolysis Combustion Flow Calorimetre (PCFC). Each case was tested in triplicate. Fig. 2 shows an example of the results obtained for each type of crop by-product. The Heat Release Rate (HRR) is represented as a function of temperature.

All the samples show a clear peak, mainly as a result of the thermal decomposition of cellulose. In some cases, a 'shoulder' is observed at lower temperatures (under $300^{\circ} \mathrm{C}$ ), which is commonly associated to the thermal decomposition of hemicellulose [7,23]. This shoulder is quite clear in rice husk and barley straw samples but is not present in corn pith. The high temperature tails that appear in all curves may be associated with lignin, the degradation temperature range of which is wide, from $200^{\circ} \mathrm{C}$ to $500^{\circ} \mathrm{C}$ [8]. Results qualitatively agree with the chemical composition shown in Table 1 despite the noticeable dispersion in values found in literature. 


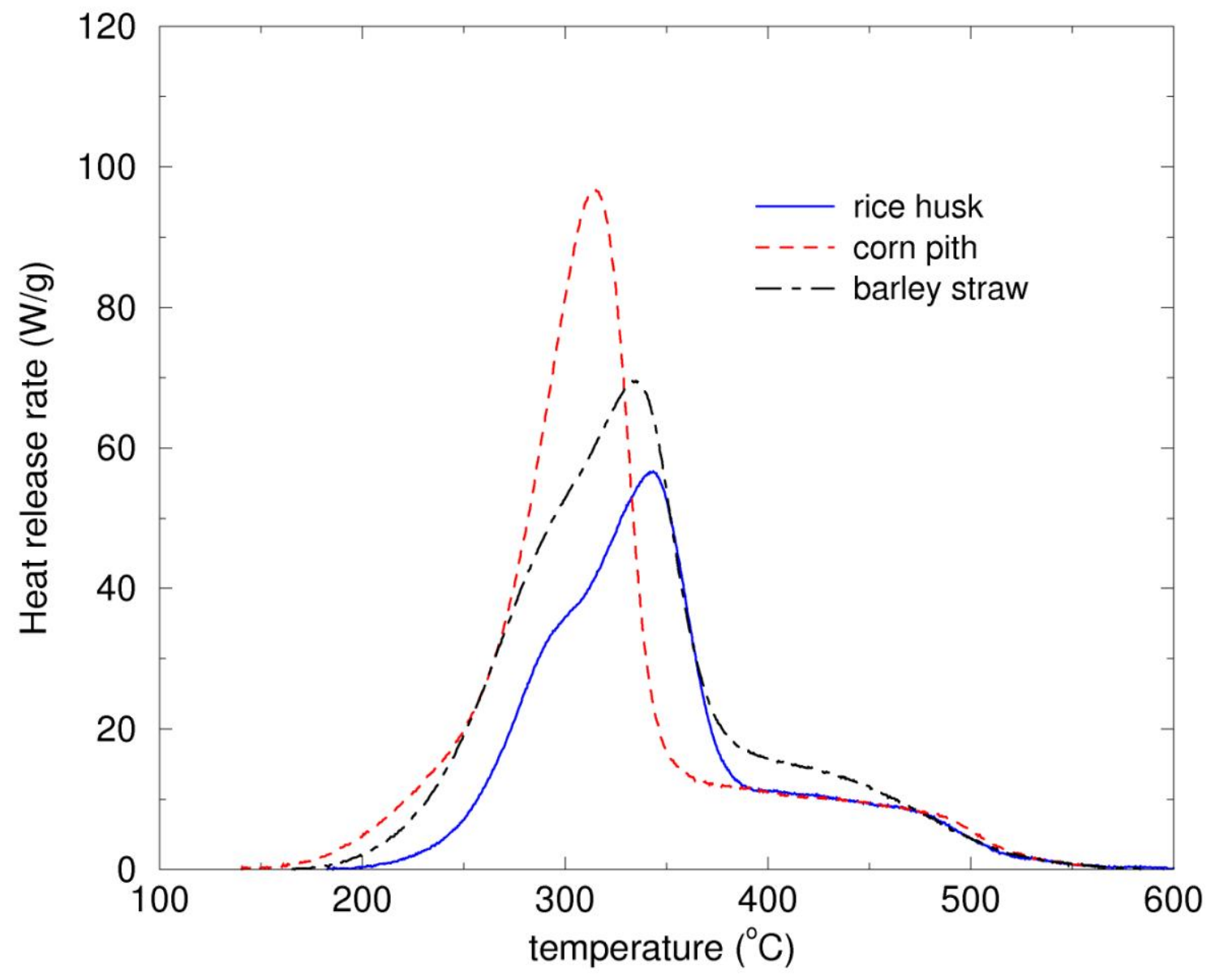

Figure 2. Heat release rate as a function of temperature for the different crop by-products.

The heat release rate for the two binders used in the natural insulations conformation is presented in Fig.3. The differences between these two binders are remarkable: whereas sodium alginate presents two peaks of a lower magnitude than peaks observed in the crop materials, starch has a sharp and much higher peak around $300^{\circ} \mathrm{C}$ (the different scales may be observed in the figure). 


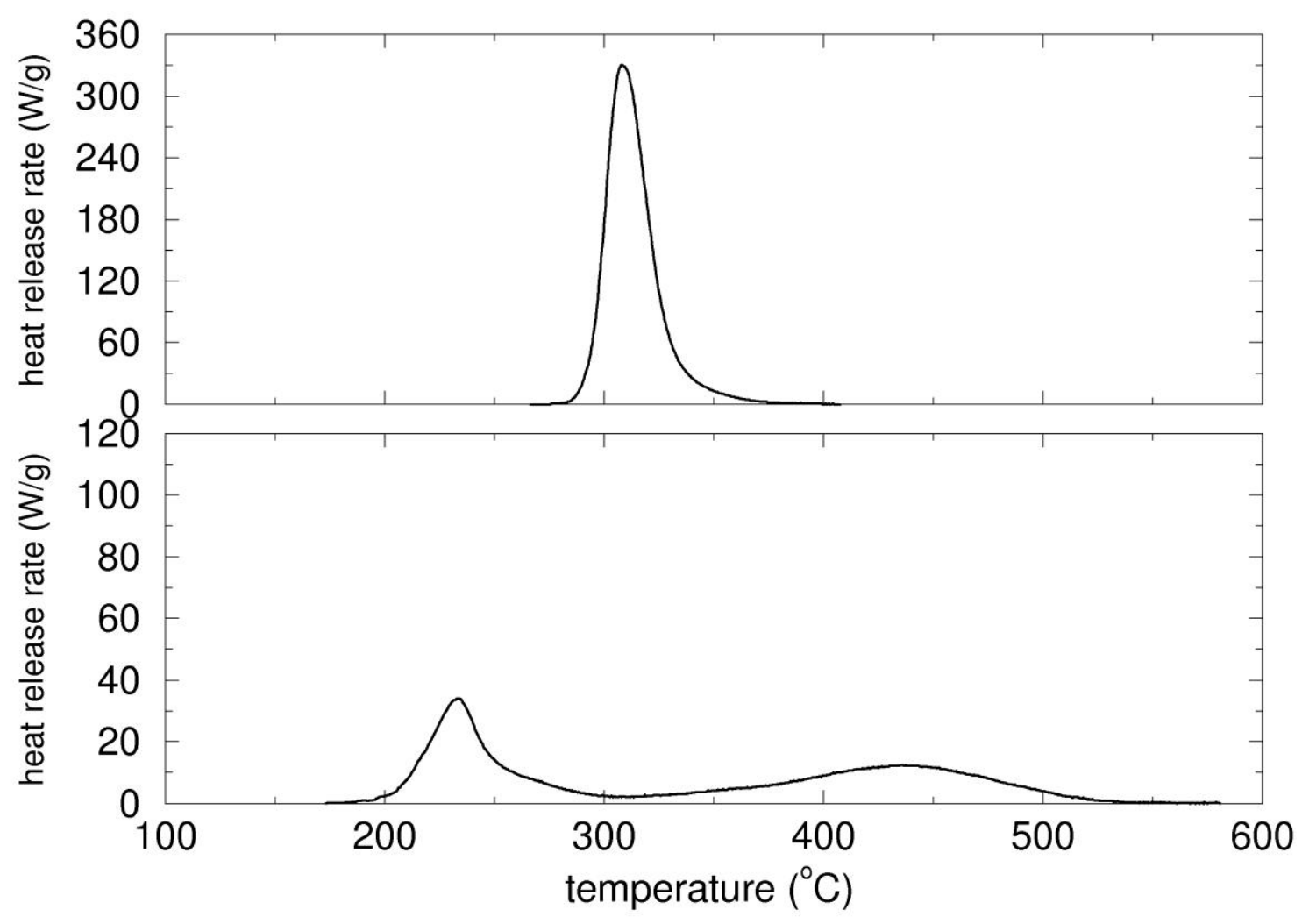

Figure 3. Heat release rate as a function of temperature for corn starch (top) and sodium alginate (bottom).

The main parameters obtained from the Pyrolysis Combustion Flow Microcalorimetre that are associated with flammability and hazard in case of fire are:

- Total heat release (HR), which is the integral of the HRR over the complete time of the test.

- Onset temperature of combustion (To), here considered as the temperature when the HRR value is $10 \mathrm{~W} / \mathrm{g}$.

- Temperature corresponding to the maximum heat release rate (Tmax)

- Maximum heat release rate (PHRR).

- Mass loss fraction (Mloss)

Table 3 summarises the results obtained for the three crop products and the two binders, averaged over three samples of each type. In addition to their agreement with Figure 2, these results show that rice husk yields the best behaviour in terms of fire protection due to the lowest 
values of HR, PHRR and Mloss. It is well known that rice contains a high content of inorganic silica. During the pyrolysis, organic components are decomposed and gasified, leaving a silica layer which can play the role of heat shield [24].

Table 3. Pyrolysis Combustion Flow Microcalorimetre results for crop by-products and binders

\begin{tabular}{llllll}
\hline Raw material & $\begin{array}{l}\mathrm{HR} \\
(\mathrm{MJ} / \mathrm{kg})\end{array}$ & $\begin{array}{l}\mathrm{T}_{0} \\
\left({ }^{\circ} \mathrm{C}\right)\end{array}$ & $\begin{array}{l}\mathrm{T}_{\mathrm{MAX}} \\
\left({ }^{\circ} \mathrm{C}\right)\end{array}$ & $\begin{array}{l}\text { PHRR } \\
(\mathrm{W} / \mathrm{g})\end{array}$ & $\begin{array}{l}\text { Mloss } \\
(\text { a.u. })\end{array}$ \\
\hline Rice husk & 5.6 & 268 & 342 & 56.4 & 0.69 \\
Corn pith & 8.8 & 215 & 312 & 92.6 & 0.73 \\
Barley straw & 8.0 & 230 & 329 & 68.3 & 0.75 \\
\hline \multirow{2}{*}{ Starch } & 9.2 & 288 & 308 & 330.5 & 0.80 \\
Alginate & 2.5 & 213 & 232 & 27.2 & 0.68 \\
\hline
\end{tabular}

\subsection{Thermogravimetric analysis of crop by-products and binders}

The two binders and the three crop by-products have been studied by thermogravimetric analysis (TG). Fig. 4 shows the results obtained for the mass loss and its derivative. Crop byproducts behaviour (left graphs) agrees qualitatively with the PCFC results shown in Table 3, the rice husk having the lowest weight loss and the lowest peak, which appears at the highest temperature. Barley straw and corn pith have a similar weight loss, but in the case of the corn pith the peak appears at a slightly lower temperature. An appreciably different behaviour is observed between the two binders (right graphs). Starch weight is reduced by $90 \%$ and the derivative presents a sharp peak with a magnitude approximately three times higher than that obtained for the alginate and the crop by-products (the different scale may be observed in the figure). This higher peak indicates a faster thermal decomposition. As was also observed in PCFC results, the main peak in the alginate occurs about $80^{\circ} \mathrm{C}$ before the peak in the starch. The second decomposition of alginate, around $400^{\circ} \mathrm{C}$ is hardly noticeable. 


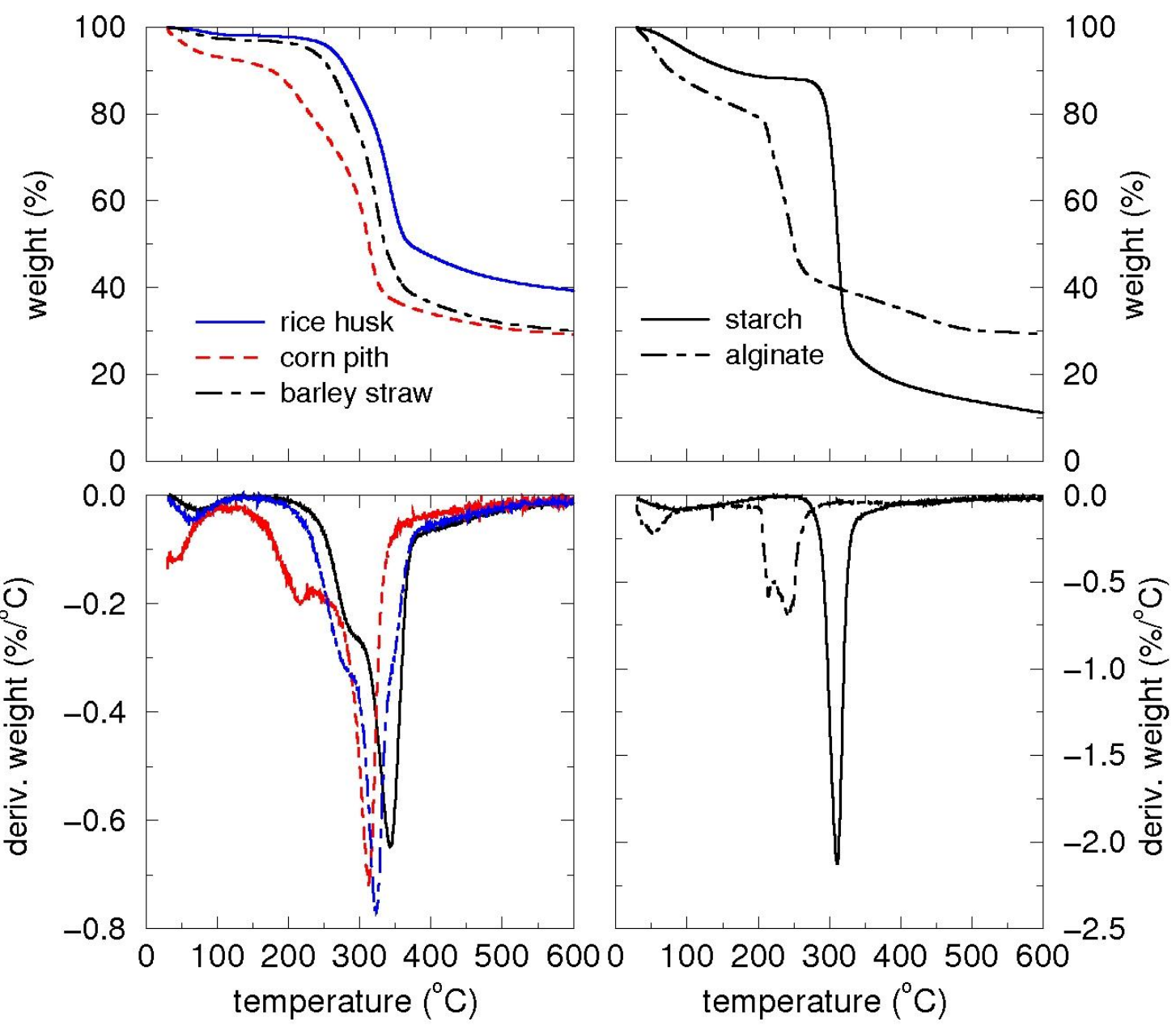

Figure 4. TGA and derivative for the three selected crop by-products and the two binders.

\subsection{PCFC analysis of natural insulation materials}

The six thermal insulation materials presented in Table 2 were analysed with the PCFC technique. The results for rice husk, corn pith and barley straw are shown in Figs 5-7, respectively. In each figure, the heat release rate of the composite is compared with that obtained for each of the two components (binder and crop by-product) separately. For each component, HRR curves (Figs. 2 and 3) are adjusted according to their percentage in the composite.

Table 4 summarises the results obtained for the six formulations averaged over three samples of each type. The higher percentages of starch, in comparison with alginate, together with its high HRR gives as a consequence that, in general, the composites show a higher HRR, and thus a 
worse fire behaviour than the corresponding crop by-product alone. This occurs specially in the case of the rice husk, where starch is about $30 \%$ of the mixture.

On the other hand, alginate has a very low contribution to the heat release and, in general, significantly improves the fire behaviour of the crop by-products. These results are compared with those obtained for other commercial organic foams (polystyrene and polyurethane), thereby confirming that insulations based on crop by-products present a better fire behaviour than organic foams (see Table 4). The HR of these foams is found to be between 2 and 6 times higher. In particular, polystyrene presents a remarkably high PHRR (about 10 times higher than bio-based insulations), which however appears later (at approximately $430^{\circ} \mathrm{C}$ ). 

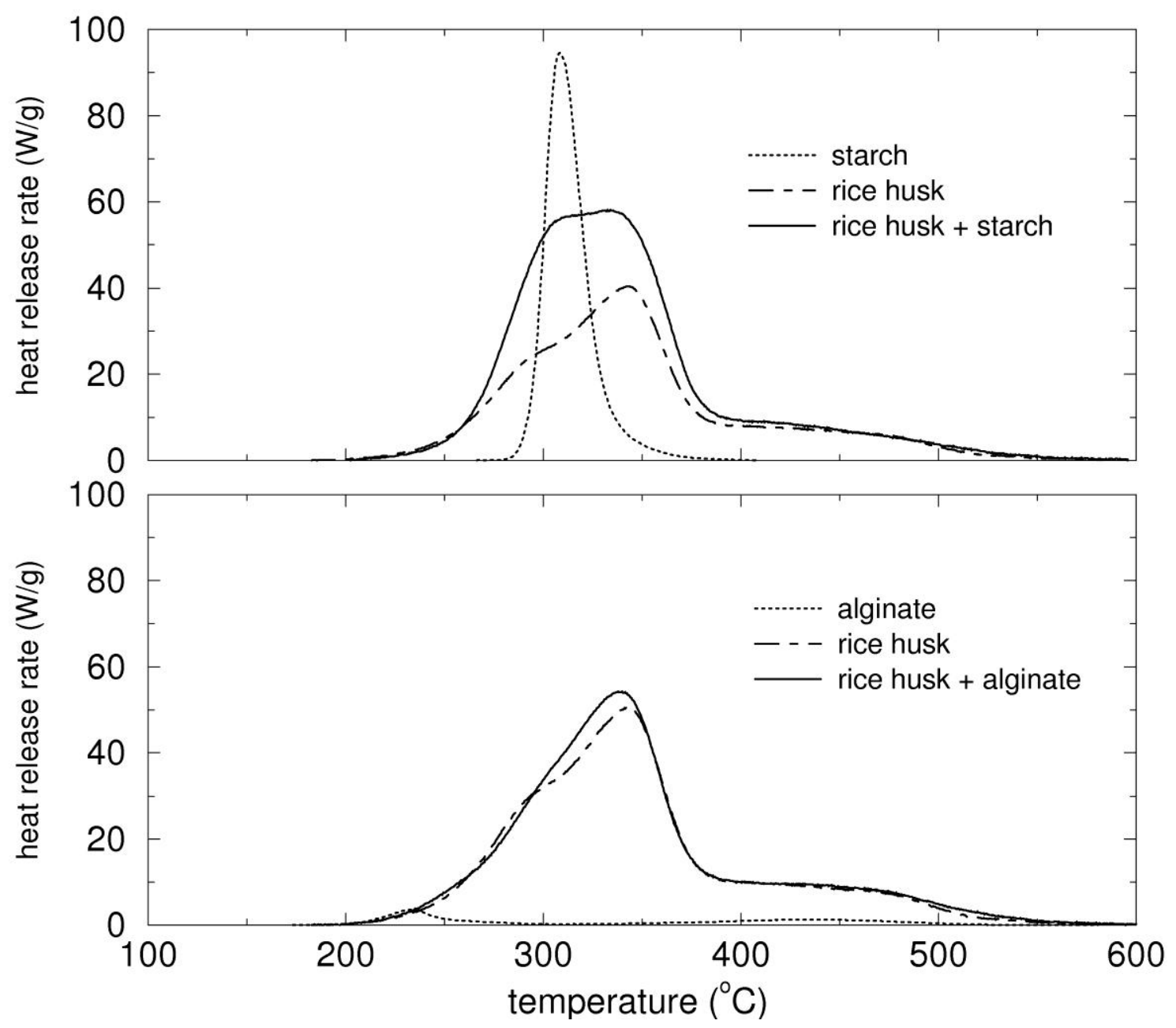

Figure 5. Heat release rate as a function of temperature for the natural thermal insulations (solid lines) formulated with rice husk and the two binders: corn starch (top panel) and sodium alginate (bottom panel). Discontinuous lines show the results for each component alone, obtained from Figs. 1 and 2 and adjusted by their percentage in the composite, as shown in Table 2 . 

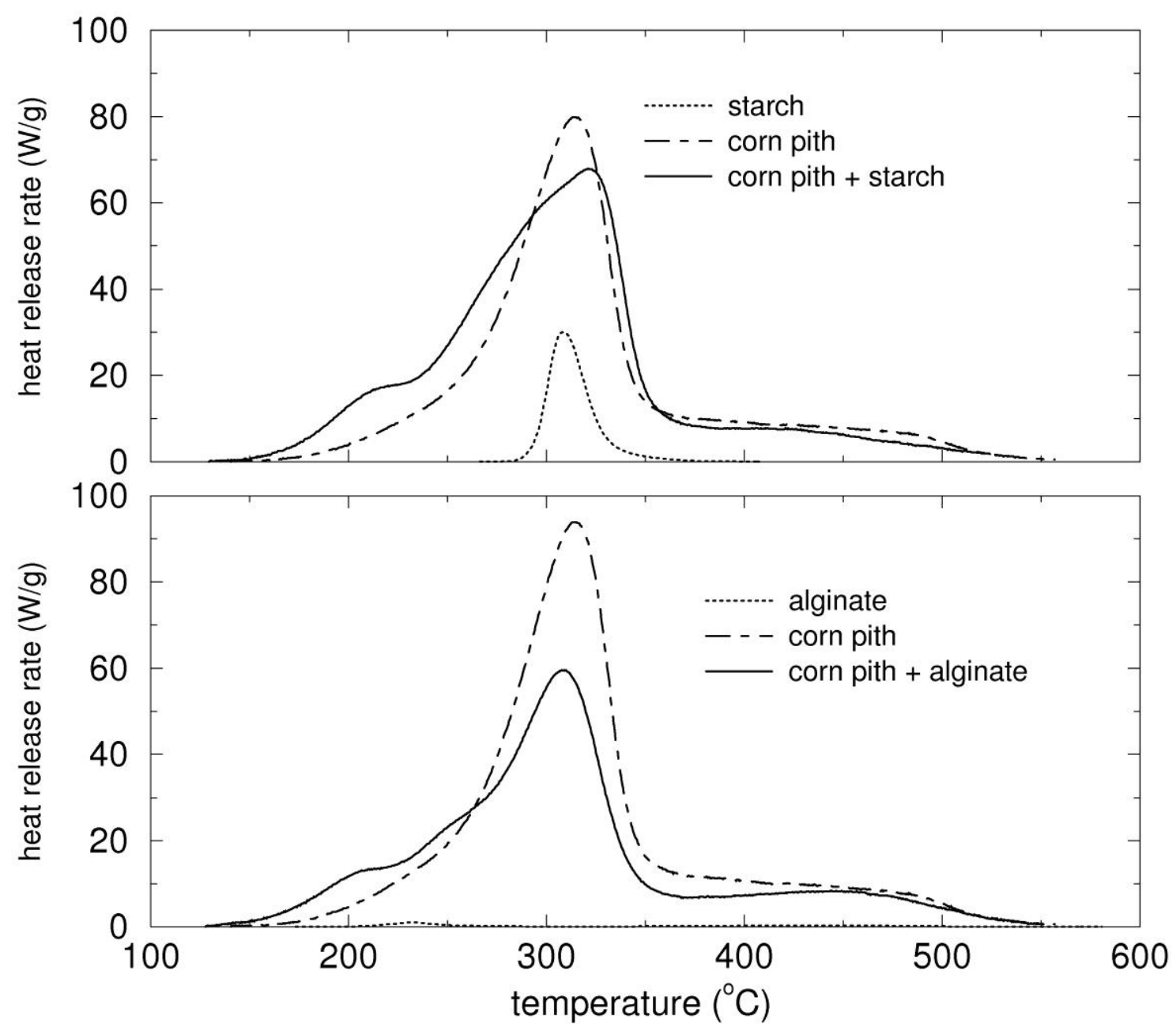

Figure 6. The same as Fig. 5 for natural insulations formulated with corn pith and the two binders, as shown in Table 2. 

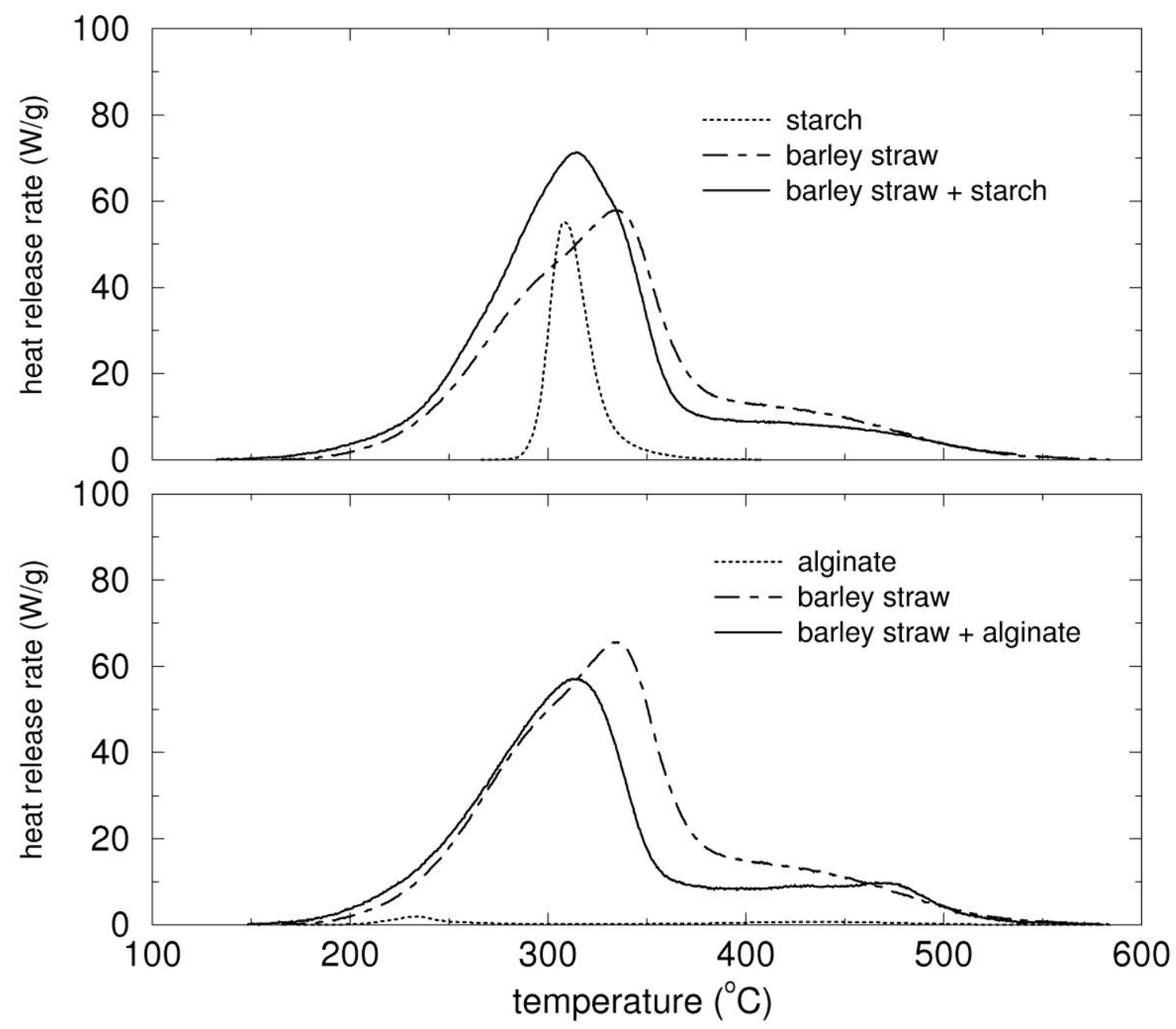

Figure 7. The same as Fig. 5 for natural insulations formulated barley straw and the two binders, as shown in Table 2.

Table 4. Pyrolysis Combustion Flow Microcalorimetre results for the natural insulators

\begin{tabular}{llllll}
\hline Thermal insulation & $\begin{array}{l}\mathrm{HR} \\
(\mathrm{MJ} / \mathrm{kg})\end{array}$ & $\begin{array}{l}\mathrm{T}_{0} \\
\left({ }^{\circ} \mathrm{C}\right)\end{array}$ & $\begin{array}{l}\mathrm{T}_{\mathrm{MAX}} \\
\left({ }^{\circ} \mathrm{C}\right)\end{array}$ & $\begin{array}{l}\text { PHRR } \\
(\mathrm{W} / \mathrm{g})\end{array}$ & $\begin{array}{l}\text { Mloss } \\
(\text { a.u. })\end{array}$ \\
\hline Rice husk + starch & 6.5 & 264 & 317 & 67.7 & 0.71 \\
Corn pith + starch & 7.0 & 199 & 313 & 61.7 & 0.77 \\
Barley straw + starch & 7.1 & 229 & 313 & 68.4 & 0.76 \\
Rice husk + alginate & 5.8 & 250 & 335 & 58.0 & 0.66 \\
Corn pith + alginate & 6.0 & 184 & 309 & 61.4 & 0.70 \\
Barley straw + alginate & 6.2 & 227 & 310 & 56.4 & 0.73 \\
\hline Polystyrene foam & 38.7 & 339 & 434 & 631.0 & 0.99 \\
Polyurethane & 13.5 & 200 & 335 & 85.0 & 0.78 \\
\hline
\end{tabular}




\subsection{Ignition time and extinguishability test for the natural insulations}

Three samples of each thermal insulation were analysed according the test described in Section 2.4. The thickness of each sample was selected in order to obtain a similar mass of $10 \mathrm{~g} \mathrm{(} \pm 1 \mathrm{~g})$ in all samples. Therefore, due to the large difference in densities (Table 2), the thicknesses ranged from $1.0 \mathrm{~cm}$ for the rice husk based materials to $3.3 \mathrm{~cm}$ for the corn pith based materials (see Table 5). The surface exposed to the radiator was $70 \times 70$ $\mathrm{mm}^{2}$ in all cases. The parameters obtained from the test, and shown in Table 5 are:

- First ignition time $\left(\mathrm{t}_{1}\right)$

- Number of ignitions in 5 minutes $\left(\mathrm{N}_{\mathrm{ig}}\right)$

- Average duration of the ignitions $\left(\Delta \mathrm{t}_{\mathrm{ig}}\right)$

- Mass loss fraction (Mloss)

On the application of the radiator, the first ignition occurred within seconds, the specimens made with rice husks taking longer. The radiator was then removed, and once the flame was extinguished a progressive smouldering was observed, with the exception of the rice husk samples. Since this test assesses the occurrence of flame, the radiator was replaced after each extinction until the 5 minutes of the assay were completed.

Table 5. Ignition and extinguishability test results

\begin{tabular}{|c|c|c|c|c|c|c|}
\hline Thermal insulation & $\begin{array}{l}\mathrm{t}_{1} \\
(\mathrm{~s})\end{array}$ & $\mathrm{N}_{\mathrm{ig}}$ & $\begin{array}{l}\Delta \mathrm{t}_{\mathrm{ig}} \\
(\mathrm{s})\end{array}$ & $\begin{array}{c}\text { Mloss } \\
(\%)\end{array}$ & $\begin{array}{c}\text { Thickness } \\
\text { (mm) }\end{array}$ & Smouldering \\
\hline Rice husk + starch & 6 & 12 & 17 & 0.65 & 10 & No \\
\hline Corn pith + starch & 2 & 3 & 15 & 0.92 & 25 & Yes \\
\hline Barley straw + starch & 5 & 9 & 14 & 0.89 & 15 & Yes \\
\hline Rice husk + alginate & 9 & 10 & 9 & 0.83 & 10 & No \\
\hline Corn pith + alginate & 2 & 1 & 7 & 0.90 & 33 & Yes \\
\hline Barley straw + alginate & 5 & 3 & 6 & 0.83 & 18 & Yes \\
\hline
\end{tabular}


The results for $\Delta \mathrm{t}_{\mathrm{ig}}$ show that the natural insulators formulated with starch have ignitions of longer duration than that formulated with alginate, and therefore a worse behaviour might be expected in case of fire. After the five minutes of the assay, and without additional application of the radiator, smouldering is observed to continue until the almost complete consumption of the samples formulated with corn pith or barley straw. The mass loss fraction Mloss shown in Table 5 is calculated once smouldering is finished. Although the rice husk samples have a greater number of long ignitions, this accounts for why their mass loss is smaller. Especially remarkable is the case of corn pith with alginate, which undergoes only one flaming ignition of short duration, but reduces its mass by $90 \%$ because of smouldering.

\subsection{Limiting Oxygen Index (LOI) results}

In general, results for LOI are in concordance with those previously recorded with the microcalorimetre and the ignition and extiguishability test. In this case, samples with the same size were compared (thus with different mass) in order to determine when consumption occurs, either with or without flame (smouldering). Rice husk composites burn at a clearly higher oxygen index than barley and corn, and corn as expected present smouldering. Nevertheless, small differences are observed between binders, indicating that this test may not be sufficient to reveal such differences.

Table 6. Oxygen Index test results

\begin{tabular}{ll}
\hline Thermal insulation & OI \\
\hline Rice husk + starch & 26.8 \\
Corn pith + starch & 18.8 \\
Barley straw + starch & 20.3 \\
Rice husk + alginate & 30.4 \\
Corn pith + alginate & 18.0 \\
Barley straw + alginate & 20.9 \\
\hline
\end{tabular}




\section{Conclusions}

The viability of experimental insulation materials based on food crop by-products (rice husk, barley straw and corn pith) and natural binders is evaluated in terms of their reaction in case of fire. PCFC results indicate that, in general, the use of alginate as a binder improves the properties of the crop by-product alone, especially in the case of corn pith, where both the total heat release HR and the peak of heat release rate PHRR are reduced by $30 \%$. It should be noticed that such improvement is achieved with a low amount of alginate $(3 \% \mathrm{w} / \mathrm{w})$, the lowest among the composites.

By contrast, results are not so positive when starch is used, especially in the case of rice husks. Since rice husk is the crop by-product with the lowest heat release, the addition of starch worsens its behaviour. PCFC results show similar behaviour for materials incorporating the same binder, regardless the crop by-product used, which indicates that binders, even in small portions, have a strong influence on the thermal degradation of the composites. In any case, the fire properties of the six experimental natural insulation materials are very favorable when compared with other organic foamy materials commonly used in building insulation, such as polystyrene and polyurethane.

Fire reaction tests on a larger scale agree qualitatively with the microgram scale PCFC results. In the ignition and extinguishability test, fewer ignitions with significantly shorter duration are observed for the materials with alginate in comparison with those containing starch. In particular, the mixture of corn pith and alginate yields an extremely good result, with only one ignition with duration of only 7 seconds. However, this result refers only to flaming combustion, and a smouldering process is also observed, which slowly burns the specimens (with the exception of the samples performed with rice husks). Such smouldering, also observed in the LOI experiments, constitutes an important problem that remains to be solved, and further research is needed to minimise this negative point. 
In our opinion, the fire behaviour of the crop by-products based insulation is a positive aspect to be added to the other benefits that, in terms of environmental impact, have in front of other commercial insulations. Although the six formulations could satisfy the necessities for their application as building insulation, our results point to the one consisting of corn pith and alginate as highly promising. It is worth pointing out that PHRR provides the results per unit of mass, but insulations made from corn pith have densities approximately 3 times lower than the others. This means that, as thermal conductivity is similar in all the cases, in a real situation the insulation made with corn pith would contain a lower mass, and therefore a lower fire load than the others.

\section{Acknowledgements}

The authors would like to thank to Generalitat de Catalunya for the quality accreditation given to the research group GICITED (2014 SGR 1298) and for the support under a PhD studentship FI-DGR. The authors also wish to express their gratitude to Cargill S.A. for kindly donating alginate and starch.

\section{References}

[1] Madurwar MV, Ralegaonkar RV, Mandavgane SA. Application of agro-waste for sustainable construction materials: a review. Constr Build Mater 2013;38:872-8.

[2] Biagotti J, Puglia D, Kenny JM. A review on natural fibre-based composites - part I: structure, properties and processing of vegetable fibres. J Nat Fibers 2004;1(2):37-68.

[3] Mohanty, AK, Misra M, and Drzal LT. Sustainable Bio-Composites from Renewable Resources: Opportunities and Challenges in the Green Materials World. J Polym Environ 2002;10(1/2):19-26. 
[4] Shea A, Lawrence M, Walker P. Hygrothermal performance of an experimental hemp-lime building, Constr aBuild Mater 2012;36:270-275.

[5] Korjenic A, Petranek V, Zach J, Hroudova J. Development and performance evaluation of natural thermal insulation materials composed of renewable resources. Energy Build 2011;43:2518-23.

[6] Chapple S, Anandjiwala R. Flammability of natural fiber-reinforced composites and strategies for fire retardancy: a review. J Thermoplast Mater 2010;23(6):871-93.

[7] Alvarez VA, Vazquez A. Thermal degradation of cellulose derivatives/starch blends and sisal fibre biocomposites. Polym Degrad Stabil 2004;84:13-21.

[8] Yao F, Wu Q, Lei Y, Guo W, Xu Y. Thermal decomposition kinetics of natural fibers: activation energy with dynamic thermogravimetric analysis. Polym Degrad Stabil 2008;93(1):90-8.

[9] Dorez G, Taguet A, Ferry L, Lopez-Cuesta JM. Thermal and fire behavior of natural fibers/PBS biocomposites. Polym Degrad Stabil 2013;98: 87-95.

[10] Rana AK, Basak RK, Mitra BC, Lawther M, Banerjee AN. Studies of acetylation of jute using simplified procedure and its Characterization. J. Appl. Polym. Sci. 1997; 64(8):1517-23.

[11] Suardana NPG, Ku MS, Lim JK. Effects of diammonium phosphate on the flammability and mechanical properties of bio-composites. Mater Des 2011;32:1990-9.

[12] Lewin M. Unsolved problems and unanswered questions in flame retardance of polymers. Polm Degrad Stab 2005;88:13-9.

[13] Patel P, Hull TR, Lyon RE, Stoliarov SI, Walters RN, Crowley S, et al. Investigation of the thermal decomposition and flammability of PEEK and its carbon and glass-fibre composites. Polym Degrad Stabil 2010;96:12-22. 
[14] Yang CQ, He Q. Applications of micro-scale combustion calorimetry to the studies of cotton and nylon fabrics treated with organophosphorus flame retardants. J. Anal. Appl. Pyrolysis 2011; 91:125-33.

[15] Lyon RE, Walters RN. Pyrolysis combustion flow calorimetry. J Anal Appl Pyrol 2002;71(1):27-46.

[16] Cogen JM, Lin TS, Lyon RE. Correlations between pyrolysis combustion flow calorimetry and conventional flammability tests with halogen-free flame retardant polyolefin compounds. Fire Mater 2009;33(1):33-50.

[17] ASTM D7309: 2007. Determining Flammability Characteristics of Plastics and Other Solid Materials Using Microscale Combustion Calorimetry.

[18] Blasi CD, Signorelli G, Russo CD and Rea G. Product distribution from pyrolysis of wood and agricultural residues. Ind. Eng. Chem. Res. 1999;38:2216

[19] Rowell RM, Rowell RM and Rowell J. Paper and composites from agro-based resources. CRC press, 1996.

[20] Sun RCa. Cereal straw as a resource for sustainable biomaterials and biofuels: chemistry, extractives, lignins, hemicelluloses and cellulose. Elsevier 2010.

[21] Demirbas A. Combustion characteristics of different biomass fuels. Prog. Energy Commun. Sci., 2004;30(2):219-230

[22] Palumbo M, Lacasta AM, Navarro A, Avellaneda J. Characterization of thermal insulation materials developed with crop wastes and natural binders. WSB14 World Sustainable Building Conference, GBC, Barcelona, 28-30 October 2014.

[23] Antal MJ, Varhegyi G. Cellulose pyrolysis kinetics - the current state knowledge. Ind Eng Chem Res 1995;34:703-17.

[24] Zhao Q, Zhang B, Quan H, Yamb RCM, Yuen RKK, Li RKY. Flame retardancy of rice husk-filled high-density polyethylene ecocomposites. Compos. Sci. Technol 2009; 69:2675-81. 